\title{
Cracking Susceptibility After Post-Weld Heat Treatment in Haynes 282 Nickel Based Superalloy
}

\author{
L.O. Osoba' ${ }^{1 \dagger}$, A.K. Khan ${ }^{2)}$ and S.O. Adeosun ${ }^{1)}$
}

1) Department of Metallurgical and Materials Engineering, University of Lagos, Nigeria

2) Department of Mechanical and Manufacturing Engineering, University of Manitoba, Winnipeg, Manitoba, Canada [Manuscript received 29 April 2013, in revised form 13 June 2013]

(c) The Chinese Society for Metals and Springer-Verlag Berlin Heidelberg

\begin{abstract}
This paper presents a study of the standard post-weld heat treatment (PWHT) behaviour of autogenous laser welded $\gamma^{\prime}$ age-hardenable precipitation strengthened nickel based superalloy Haynes 282 (HY 282). The study involves a careful and detailed microstructural characterisation as well as an analysis of the weld cracking susceptibility during welding and Gleeble thermo-mechanical physical simulation. Various factors that could influence post-weld cracking in superalloys weld were experimentally examined. Our microstructural examination of the as-solution heat treated (SHTed) material and the thermo-mechanically refined grain material shows that intergranular heat affected zone (HAZ) cracking is observable in only the as-welded SHTed material. There was no indication of post-weld heat treatment cracking in all welded materials. Our conclusion, in this study, is that the chemistry of superalloy HY 282 which aids the preclusion/ formation of deleterious solidification microconstituents during welding as well as its relatively slow aging kinetics enhances its resistance to PWHT cracking.
\end{abstract}

KEY WORDS: Cracking; Microstructure Analysis; Nickel based Superalloy

\section{Introduction}

Haynes $282^{\mathrm{TM}}(\mathrm{HY} 282)$ is a $\gamma^{\prime}$ precipitation strengthened nickel based superalloy developed in 2005 to meet the challenges of higher service temperature requirement of turbine engines used in power generation and aviation industries. The alloy exhibits unique combinations of excellent high temperature mechanical properties and good processing capabilities superior to existing and commonly used precipitation strengthened superalloys such as Waspaloy, Inconel 718, Haynes 263 and Rene $41^{[1,2]}$. Turbine components, manufactured from the precipitation hardenable nickel-base superalloy family, are often used in a harsh and hostile environment. During the prolonged period of usage, the components experience very severe thermal and mechanical stresses which cause degradations, wear and sometimes catastrophic

† Corresponding author. Ph.D.; Tel.: +234 8054269424; E-mail address: losoba@unilag.edu.ng (L.O. Osoba)

DOI: DOI: 10.1007/s40195-013-0252-3 failure. During the fabrication of new turbine engine components and/or during repairs of service damaged parts, fusion welding techniques are often employed. However, the use of the fusion welding technique, especially the high energy density process such as laser and electron beam welding, to fabricate or repair $\gamma^{\prime}$ precipitation hardened nickel-base superalloys is limited. This is because these superalloys are highly susceptible to cracking, predominantly in the heat affected zone (HAZ) ${ }^{[3]}$. Cracking sometimes also occurs in the fusion zone (FZ) during welding and/or during subsequent post-weld heat treatment $(\mathrm{PWHT})^{[4]}$. In practice, after fabrication and/or repair process, welded superalloy components are deployed in service after the components have been subjected to post-weld heat treatment cycle. The postweld heat treatment cycle is designed to restore the microstructure and properties of the welded components that may have been altered by the preweld heat treatment and welding process ${ }^{[5]}$. Superalloy HY 282 has been found to be susceptible to HAZ liquation cracking ${ }^{[6,7]}$. The reason why the newly developed 
HY 282 alloy is susceptible to liquation cracking in SHT condition but resistance to weld cracking by using a suitable preweld microstructural modification has been fully discussed by the current authors in another communication ${ }^{[8]}$. Although, post-weld heat treatment cracking is known to limit the fabricability and repair of superalloy components, however, there are few published discussions on the PWHT behaviour of laser welded superalloy HY 282. Therefore, this paper is a report of the results of our study of PWHT response of superalloy HY 282 using manufacturer standard heat treatment procedure.

\section{Experimental}

The HY 282 materials used in this study were provided by HAYNES International Inc. Kokomo USA in the form of mill bright-annealed plates of dimensions $610 \mathrm{~mm} \times 120 \mathrm{~mm} \times 11.5 \mathrm{~mm}$. The chemical composition (wt.\%) of the material supplied by the manufacturer was Al 1.5, Ti 2.1, Co 10, Cr 20, Mo 8.5, Fe 1.5, Mn 0.3, Si 0.15, C 0.06, B 0.005 and Ni balanced. Rectangular welding test specimen with dimension of $65 \mathrm{~mm} \times 15 \mathrm{~mm} \times 5 \mathrm{~mm}$ was machined from the asreceived and the thermo-mechanically refined grain material by a numerically controlled wire electrodischarge machine (EDM). The as-received machined specimen was subjected to the recommended pre-weld solution heat treatment (SHT), using a Marshal tube furnace connected to a digital programmer. The heat treatment procedure is $1120{ }^{\circ} \mathrm{C} / 2 \mathrm{~h} / \mathrm{WQ}-\mathrm{SHT}$; refine grain + SHT which is $1080{ }^{\circ} \mathrm{C} / 2 \mathrm{~h} / \mathrm{FC} ; 1120^{\circ} \mathrm{C} / 2 \mathrm{~h} /$ $\mathrm{WQ}+1010{ }^{\circ} \mathrm{C} / 2 \mathrm{~h} / \mathrm{AC}+788^{\circ} \mathrm{C} / 8 \mathrm{~h} / \mathrm{AC}-\mathrm{PWHT}(\mathrm{AC}$ air-cooled, WQ water-quenched, FC furnace-cooled, PWHT post weld heat treatment). The hardness value of the as-received and all the heat treated samples were determined using $10 \mathrm{~kg}$ load on Vickers hardness testing machine. An average of ten (10) hardness was recorded for each specimen. The preweld heat-treated specimen was surface ground, properly cleaned to remove surface oxides and then, autogenously welded by a single pass $\mathrm{CO}_{2}$ laser beam. The welding parameter was as follows: heat input $80 \mathrm{~J} / \mathrm{mm}$, power $2 \mathrm{~kW}$, speed $1.5 \mathrm{~m} / \mathrm{min}$, beam focus -2 , shielding gas flow rate $30 \mathrm{~L} / \mathrm{min}$, welding gas flow rate $25 \mathrm{~L} / \mathrm{min}$. Selected autogenously welded specimens were further subjected to the manufacturer standard PWHT procedure ${ }^{[1]}$. The laser beam welded specimen and standard PWHT specimen were sectioned transversely to the welding direction (by the EDM) to produce 10 sections each from the specimen. In order to evaluate and study microstructural changes in the HAZ during welding and PWHT, physical simulation was performed by using Gleeble 1500-D thermomechanical simulation system. The simulation was performed at a rapid heating rate of $150{ }^{\circ} \mathrm{C} / \mathrm{s}$ to peak temperature of $1230{ }^{\circ} \mathrm{C}$. It was held for $0.5 \mathrm{~s}$ and rapidly cooled to preserve, as much as possible, the microstructural changes that ensued at the peak temperatures. As-received, preweld heat-treated, welded, PWHTed and Gleeble simulated cut sections were mounted in bakelite, ground and polished using standard metallographic techniques for microstructural study. The metallographic specimens were chemically etched with the use of modified Kallings reagent $(40 \mathrm{~mL}$ distilled water $\left.+480 \mathrm{~mL} \mathrm{HCl}+48 \mathrm{~g} \mathrm{CuCl}_{2}\right)$ and electrolytic etched with $10 \%$ oxalic acid at $6 \mathrm{~V}$ for 3 $5 \mathrm{~s}$. The microstructures of the as-received, pre-weld heat treated, welded and PWHTed specimen were initially examined by optical microscopy with the use of a ZEISS Axiovert 25 inverted- reflected light microscope, equipped with CLEMEX Vision 3.0 image analysis software. A detailed microstructural study and spectroscopy analysis were carried out by using a JEOL 5900 scanning electron microscope (SEM) and a JEOL 2100F (scanning) transmission electronmicroscopy ((S)TEM). Both microscopes were equipped with Oxford energy-dispersive spectrometer (EDS). TEM specimens are prepared by mechanical grinding $3 \mathrm{~mm}$ diameter discs to $\sim 100 \mu \mathrm{m}$. The $100 \mu \mathrm{m}$ thin foils were then dimpled to $50 \mu \mathrm{m}$ and then twin-jet electropolished in a solution of $10 \%$ perchloric acid, $90 \%$ methanol at $243 \mathrm{~K}$ and $20 \mathrm{~V}$. The extent of HAZ and PWHT cracking were determined by measuring the total crack length in the 10 sections of welded specimen by SEM (operated in both secondary and backscattered imaging mode).

\section{Results and Discussion}

\subsection{Microstructural analysis of pre-weld heat treated and laser welded HY 282 alloy}

Fig. 1 shows the SEM micrograph of the pre-weld solution heat treated and the refined grain material. The average grain size of the solution heat treated (Fig. 1(a)) and refine grain material (Fig. 1(b)) is $\sim 140 \mu \mathrm{m}$ and $\sim 40 \mu \mathrm{m}$, respectively. The microstructure consisted of intergranular and intragranular primary MC carbides based on titanium and molybdenum and chromium based $\mathrm{M}_{23} \mathrm{C}_{6}$ carbides, all of which had been previously reported to form in the alloy $^{[1-2,8]}$. The $\gamma^{\prime}$ main strengthening phase was not observed by the SEM. Fig. 2 shows the optical micrograph of a general weld region of the laser welded plus PWHTed material. In all welded specimens, there was the absence of cracks in the FZ independent of the preweld heat treatment conditions, which was consistent with earlier reported investigations ${ }^{[6-8]}$. Although there was no cracking in FZ of welded specimens, the HAZ of the solution heat treated welded alloy suffered varying degree of intergranular cracking (Fig. 3 and Fig. 4). However, the HAZ of the refined grain material was crack-free (Fig. 5). Significant portion of the cracks in the SHT welded material were located in the neck area of the keyhole shaped weld, of the HAZ region away from the FZ. Some of 

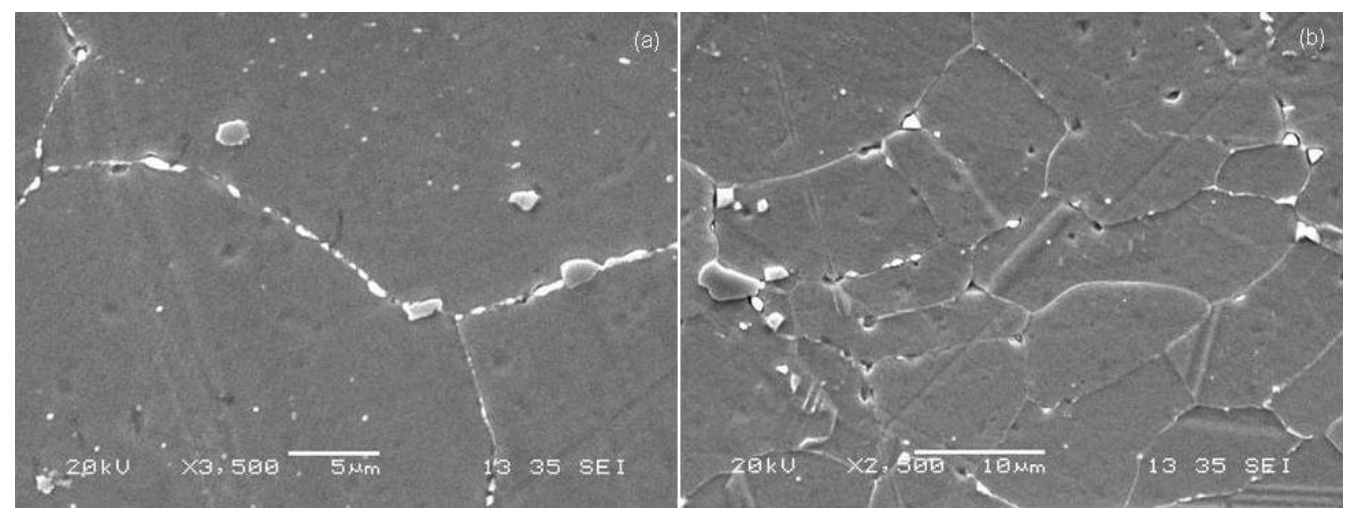

Fig. 1 SEM images of the solution heat treated alloy (a) and thermomechanically refine grain alloy (b)

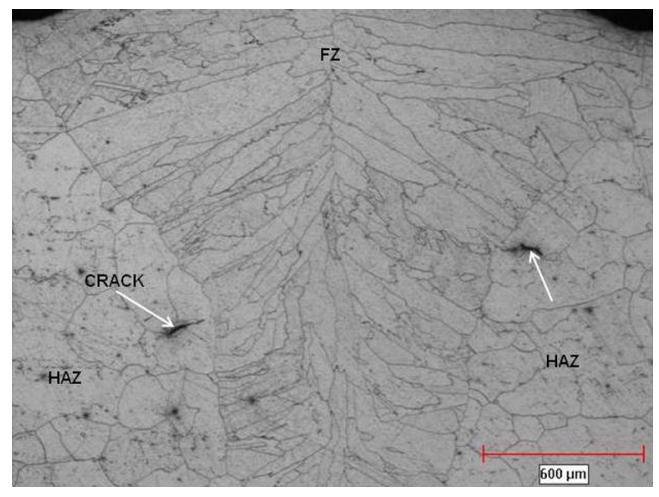

Fig. 2 Optical micrograph of laser welded + PWHTed HY 282 alloy showing the general overview of the PWHTed material

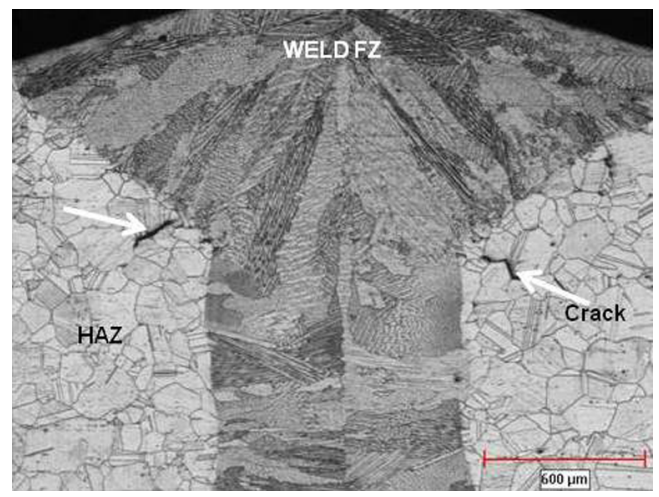

Fig. 3 Optical micrograph of laser welded HY 282 alloy showing the general overview of the laser welded material

the main features of the cracks included irregular zigzag morphology of the fracture path and close association with widened grain boundaries, which are typical features of intergranular liquation cracking.

\subsection{General response of Haynes alloy 282 to post-weld heat treatment}

In order to investigate the post-weld heat treatment response of HY 282 alloy, three (3) different sets
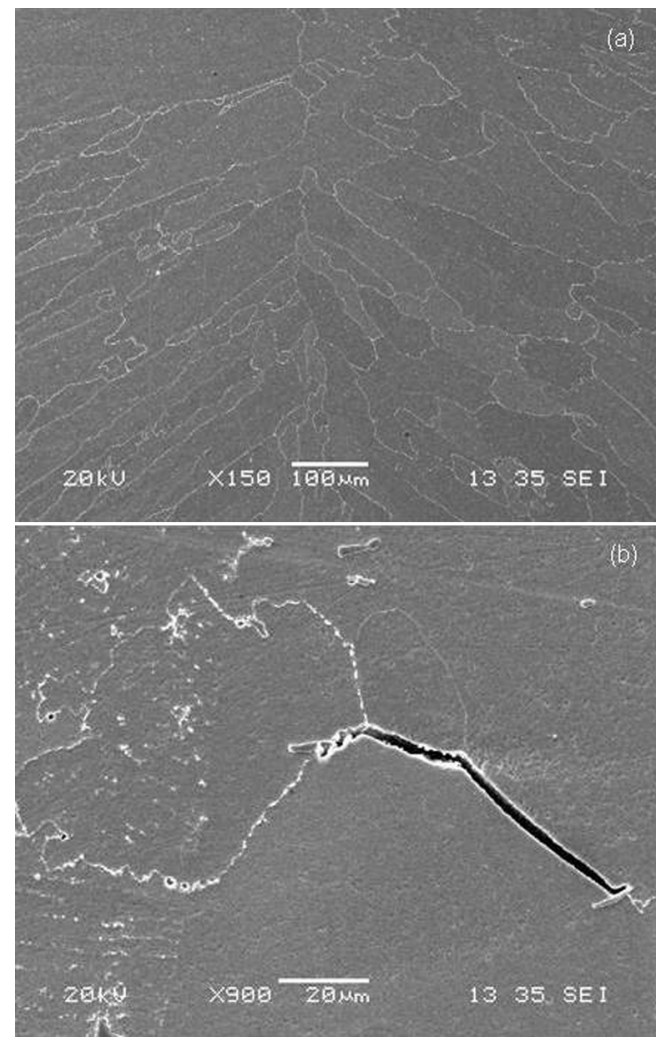

Fig. 4 SEM micrographs of PWHTed laser welded specimen showing FZ microstructure without crack (a) and HAZ microstructure (b)

of as-welded SHT and refined grain specimens were PWHTed using the standard heat treatment procedure $\left(1120{ }^{\circ} \mathrm{C}\right.$ for $2 \mathrm{~h} \mathrm{WQ}+1010{ }^{\circ} \mathrm{C}$ for $2 \mathrm{~h} \mathrm{AC}+$ $788^{\circ} \mathrm{C}$ for $\left.2 \mathrm{~h} \mathrm{AC}\right)$. Following the heat treatment, the weld FZ and HAZ microstructures were examined by using SEM. In addition, the extent of HAZ cracks in ten (10) sections each of the as-welded specimen and those specimens subjected to the pre-weld plus postweld heat treatment, were measured by using SEM. There is no indication of the strengthening $\gamma^{\prime}$ precipitates in the microstructure examined. Detailed TEM/EDS analysis of the FZ solidification product in the as-welded material had previously indicated that 
Table 1 HAZ cracking susceptibility of laser welded +PWHTed HY 282 alloy

\begin{tabular}{|c|c|c|c|c|c|}
\hline $\begin{array}{c}\text { Total crack length } \\
(\mu \mathrm{m})\end{array}$ & $\begin{array}{l}\text { Average to } \\
\text { Section- }\end{array}$ & $\begin{array}{l}\text { rack length/ } \\
\mathrm{L} / \mathrm{S}(\mu \mathrm{m})\end{array}$ & $\begin{array}{r}\text { Total num } \\
\mathrm{crac}\end{array}$ & bers of & $\begin{array}{c}\text { Maximum crack } \\
\text { length - MCL }(\mu \mathrm{m})\end{array}$ \\
\hline As-welded PWHT & As-welded & PWHT & As-welded & $\overline{\mathrm{PWHT}}$ & As-welded PWHT \\
\hline 1300 & 51 & 52 & 24 & 22 & 168 \\
\hline
\end{tabular}

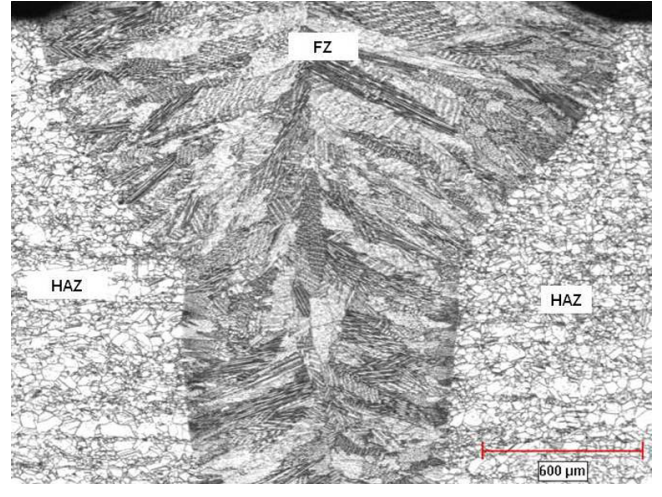

Fig. 5 An optical micrograph showing typical crack-free weld section in laser welded HY 282 alloy with refined grains

MC carbide was the principal resolidification product in the $\mathrm{FZ}^{[7]}$. This analysis also confirmed the absence of $\gamma^{\prime}$ precipitates or deleterious phases, like $\gamma-\gamma^{\prime}$ eutectic product ${ }^{[7]}$. Although TEM/EDS analysis of the FZ of the as-welded material did not show formation of $\gamma^{\prime}$ precipitates within the fusion zone and the selected area electron diffraction pattern (SAEDP) did not reveal any superlattice reflections of the $\gamma^{\prime}$ phase, Fig. 6(a) and Fig. 6(b) show the TEM dark field image and SAEDP from [001] zone axis of the FZ of the PWHTed material. The image reveals the supperlattice reflection of the $\gamma^{\prime}$ main strengthening phase, which is an indication of considerable strengthening of the matrix during PWHT.

The results of HAZ total crack length (TCL), total number of cracks (TNC) and maximum crack length (MCL) measured in as-welded and PWHTed specimens are presented in Table 1. Analysis of HAZ cracks measured in as-welded and PWHTed specimens did not reveal significant differences in the severity of cracking in the PWHTed specimen compared to those observed in the as-welded specimen. There was no appreciable increase in the value of TCL, TNC and MCL in all of the as-welded plus PWHTed specimen examined. Moreover, the thermo-mechanically refined grain specimen that was free of intergranular crack in the as-welded condition was similarly crack-free after being subjected to post-weld heat treatment. A micrograph that shows the crack-free weld region in the alloy with refined grains is presented (Fig. 5). The result of the cracking measurements obtained in the present study after the PWHT of the as-welded specimen is not in agreement with previous findings in other precipitation strengthened alloys $^{[5,9,10]}$.

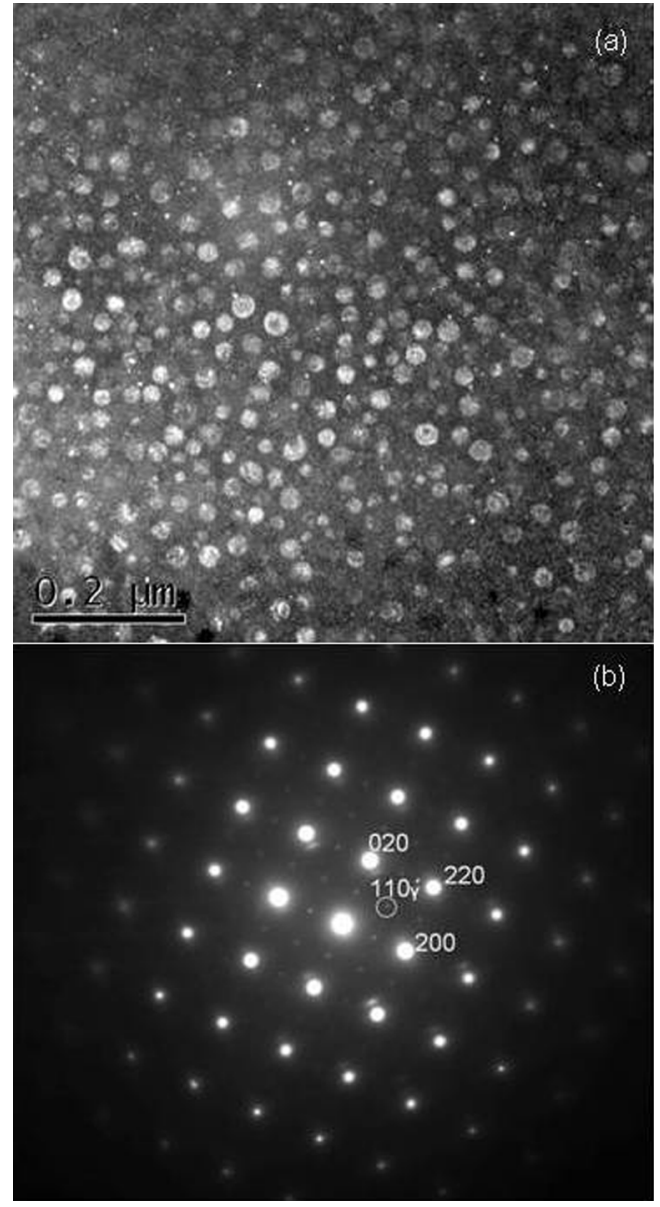

Fig. 6 (a) TEM dark field image of the FZ of the PWHTed alloy and (b) SAEDP from 001 zone axis of the $\gamma$ matrix, showing superlattice reflection typical of intermetallic $\gamma^{\prime}$ phase

\subsection{On the absence of post-weld heat treatment crack- ing in Haynes alloy 282}

Hot cracking in superalloys weldment during fabrication and repairs and/or during the subsequent post-weld heat treatment performed on the weldment, has been generally attributed to either mechanical or metallurgical factors or both. Previous investigations on the mechanism of PWHT cracking in several nickel-base alloys ${ }^{[4,9,11-14]}$ have indicated that PWHT cracking occurs when aging contractions stresses that developed during PWHT are relaxed preferentially in the HAZ, which has already been embrittled by various metallurgical reactions during welding. Other stresses contributing to PWHT cracking include the residual welding stresses. The metallurgical factors affecting PWHT cracking in nickel- 
base alloys are considered to be chemical compositions, grain size, grain boundary precipitates and the pre-weld conditions of the parent material. Alloys with very fast precipitation kinetics owing to $\mathrm{Al}+\mathrm{Ti}$ wt. $\%$ and sizeable volume fraction of gamma prime $\left(\gamma^{\prime}\right)$, such as in IN 738, Rene 41 and Waspaloy are known to be highly susceptible to PWHT cracking. In alloys, where precipitation strengthening is achieved by the addition of niobium rather than $\mathrm{Al}+\mathrm{Ti}, \gamma^{\prime \prime}$ precipitate is the main strengthening phase. For example in IN 718, strengthening is achieved by the addition of niobium, forming $\gamma^{\prime \prime}$, with $\sim 15 \%$ volume fraction. Alloys that are predominantly strengthened by the $\gamma^{\prime \prime}$ phase are generally believed to be more resistant to PWHT cracking. A recent work by Krenz et al. ${ }^{[15]}$ on IN 718 however shows that the presence of initial welding cracks in the alloy can reduce its resistance to PWHT cracking. A major consequence of niobium in the chemistry of superalloys is the propensity to form laves phase (a resolidification product on liquated HAZ grain boundaries) during welding. Niobium also influences the precipitation of $\gamma^{\prime}$ and $\gamma^{\prime \prime}$ and cause its sluggish precipitation and aging response. Laves phase is generally brittle with weak interface with gamma matrix ${ }^{[16]}$. Laves phase also serves as preferential site for easy crack initiation and/or propagation because of its inability to accommodate strain aging stress during post-weld heat treatment. In the current study of alloy HY 282, there was no evidence of new crack formation or a significant propagation of initial cracks, in terms of crack extensions during PWHT. Therefore, experiments were designed to first study the precipitation and aging kinetics of the new HY 282 alloy viz-a-viz that of IN 718+ alloy. More so, IN 718+ alloy and HY 282 alloy are among the nickel-base superalloys developed in the last decade for improved high temperature stability and strength compared to baseline IN 718 alloy. The hot working temperature of IN $718+$ is $700{ }^{\circ} \mathrm{C}$ (approximately $50{ }^{\circ} \mathrm{C}$ above the limit for IN718) while that of $\mathrm{HY}$ 282 alloy is in the range from $800^{\circ} \mathrm{C}$ to $900^{\circ} \mathrm{C}^{[2]}$. IN $718+$ has been reported to exhibit some level of resistance to weld cracking when welded in certain preweld heat treatment conditions. However, IN 718+ cracks during post-weld heat treatment ${ }^{[11]}$. In both alloy of HY282 and IN $718+, \gamma^{\prime}$ is the predominant precipitation strengthening phase. The Al+Ti wt.\% content in HY 282 is expected to influence its susceptibility to cracking during welding and during PWHT is $3.6 \%{ }^{[2]}$, which is higher than $2.2 \%$ in IN $718+{ }^{[17]}$. Furthermore, an estimate of the volume fraction of the strengthening phase $\gamma^{\prime}$, in HY 282 and IN 718+, is determined from SHT- $1050{ }^{\circ} \mathrm{C}$ furnace cool material using CLEMEX Vision 3.0 image analysis software. The results show that the volume fraction/number density of the $\gamma^{\prime}$ phase in HY 282 alloy is comparatively fewer than in IN $718+$ (Fig. 7). The $\gamma^{\prime}$ volume fraction analysis results appear to agree with the reported estimate in HY $282(19 \%)^{[2]}$ and IN $718+(21 \%)^{[2,17]}$.

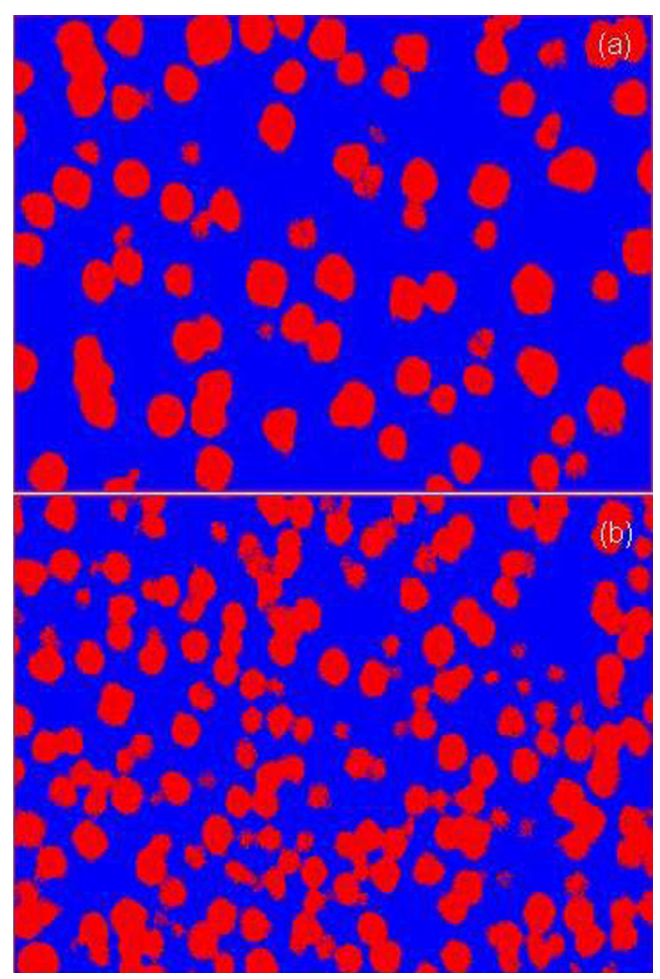

Fig. 7 Volume fraction image analysis of $\gamma^{\prime}$ precipitates in HY 282 alloy (a) and IN 718+ alloy (b)

Aside from $\mathrm{Al}+\mathrm{Ti}$ content, $\mathrm{Nb}$ is also known to influence gamma prime volume fraction in superalloy. The relatively higher gamma prime volume fraction in alloy IN 718+ compared to HY 282 alloy despite the higher $\mathrm{Al}+\mathrm{Ti}$ content in $\mathrm{HY} 282$ can be related to the presence of $\mathrm{Nb}$ in the chemistry of IN 718+.

Hardness test was conducted after subjecting $\mathrm{HY}$ 282 alloy and IN $718+$ specimen to solution heat treatment at $1050{ }^{\circ} \mathrm{C}$ for $1 \mathrm{~h}$ (the temperature is above the solvus of the main strengthening phase, $\gamma^{\prime} \sim 1000{ }^{\circ} \mathrm{C}$ ) followed by aging at $816{ }^{\circ} \mathrm{C}$ for varying length of time. The result, as shown in Fig. 8, indicates that $\gamma^{\prime}$ precipitation (as reflected in the hardness after solution treatment before aging in Fig. 8) is much rapid in HY 282 alloy than in IN718+. Generally, the $\gamma^{\prime}$ precipitation kinetics and its growth in age hardenable alloys is known to increase with increase in $\mathrm{Al}+\mathrm{Ti}$ content and $\gamma^{\prime}$ volume fraction. However, in the present study, aging response of IN 718+ alloy appears rather more rapid than that of HY 282 alloy (see Fig. 8) despite the lower Al+Ti wt.\% content of IN $718+$. This can be attributed to the influence of other solute elements aside from $\mathrm{Al}+\mathrm{Ti}$ on the volume fraction of the strengthening $\gamma^{\prime}$ phase, in that, the $\gamma^{\prime}$ volume fraction in IN 718+ $(21 \%)$ is comparatively slightly more than in HY 282 alloy (19\%). Addition of certain alloying elements, such as Mo and $\mathrm{W}$ are known to have effect of slowing down diffusion processes, for example, aging kinetics, which may consequently influence the susceptibility to post-weld heat treatment cracking ${ }^{[18]}$. Niobium has a slow dif- 


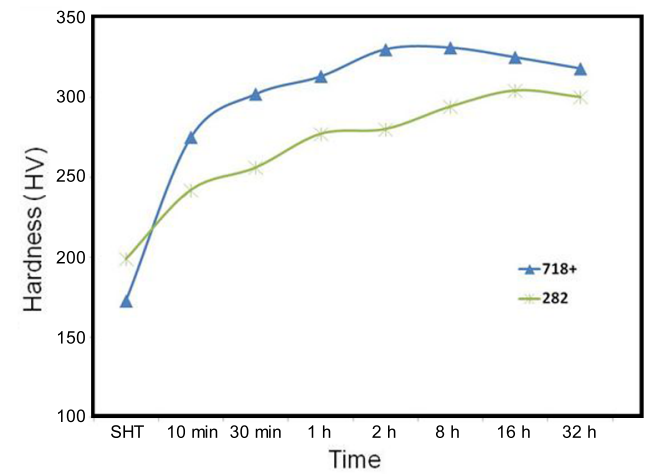

Fig. 8 Variation in Hardness during aging of Haynes alloy 282 and IN718+ alloy

fusivity in $\gamma^{\prime}$ austenite. However, whilst this may just be adequate enough to slow down precipitation and aging kinetics of the $\gamma^{\prime}$ and $\gamma^{\prime \prime}$ strengthening phase, it may not be able to mitigate formation of deleterious laves phase in $\mathrm{Fe}$ containing Ni-based superalloy like IN718 and IN718+. Although the deleterious embrittling phase on existing welding cracks serves as initiation sites that aid further crack propagation in IN718 and IN718+ alloy ${ }^{[11,15,16]}$, there is no significant increase in cracking during PWHT of HY 282 alloy. Interestingly, the rupture life during creep test (having similar mechanism to PWHT cracking) of HY 282 has been reported to increase with Mo content up to about 8.5 wt.\% (max. content in HY 282) and subsequently decreases rapidly with increase in Mo content $^{[2]}$.

For verification and comparisons of the alloys microstructure after post-weld heat treatment, Gleeble thermo-mechanical physical simulation of the HAZ microstructure was performed on HY 282 and IN $718+$ alloy, at peak temperature of $1230{ }^{\circ} \mathrm{C}$ for 0.5 s. Before simulation, the two alloys were subjected to the standard solution heat treatment (for IN $718+$ at $950{ }^{\circ} \mathrm{C}$ ) for one hour. Subsequent to the Gleeble simulation, the alloys were subjected to the recommended standard post-weld heat treatment (for IN $718+$, at $950{ }^{\circ} \mathrm{C}$ for $1 \mathrm{~h}, \mathrm{AC}+788^{\circ} \mathrm{C}$ for 8 $\mathrm{h}, \mathrm{AC})$. Microstructural examination of the Gleeble simulated PWHT specimen shows that the IN 718+ alloy has dense network of laves-type and needle-like delta $(\delta)$ phases $^{[10,16]}$ mostly along intergranular region (Fig. 9). As earlier mentioned, the laves phase formed during welding while the delta phase precipitated out during post-weld heat treatment and was incoherent with the $\gamma$ matrix ${ }^{[16]}$. In contrast, the intergranular region in the Gleeble simulated Haynes alloy 282 specimen was laced with mostly carbide particles (Fig. 10) and devoid of any embrittling laves and delta phase. Presence of embrittling laves and formation of delta phase on liquated HAZ grain boundary during post-weld heat treatment has been reported as a major factor responsible for the post-weld heat treatment cracking that occurs in IN $718+{ }^{[10]}$. It

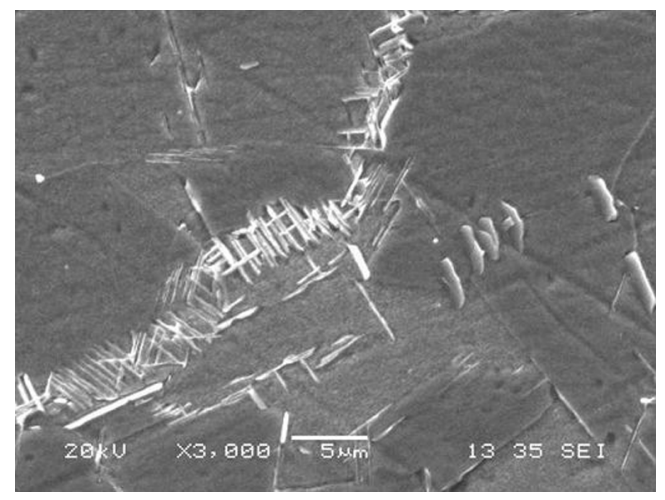

Fig. 9 SEM image of simulated PWHT-HAZ microstructure of IN $718+$, showing the dense network of laves and delta $(\delta)$ phase

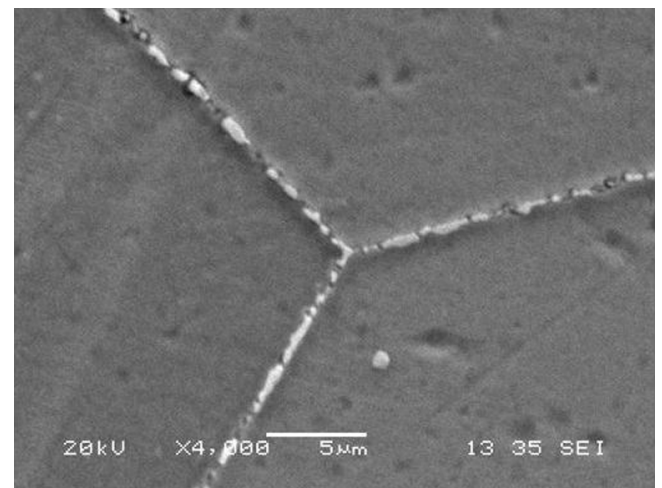

Fig. 10 SEM image of simulated PWHT-HAZ microstructure of Haynes alloy 282

is thus obvious, from these results, that the nature of the intergranular precipitates in the Gleeble simulated post-weld heat treated specimens of IN $718+$ and HY 282 is different. This major difference in the nature of PWHTed grain boundary precipitates as well as the relatively slow aging response is considered responsible for the behaviour of the HY 282 during post-weld heat treatment. The result of the microstructural examination of the laser welded plus post-weld heat treated specimen as well as the Gleeble HAZ simulated plus post-weld heat treatment specimen suggests that the resistance to post-weld heat treatment cracking in HY 282 alloy may be attributed to the chemistry of the alloy as designed. Thus, the absence of niobium in the chemistry, precluded the formation of deleterious laves and delta phases during the welding and subsequent post-weld heat treatment. Absence of deleterious phases, like laves and delta in the alloy after welding and during post-weld heat treatment as well as the comparatively slow aging response of HY 282 alloy, may have minimized the magnitude of aging contraction stresses and attendant matrix stiffening effect on HAZ grain boundaries. The comparative slow aging response of alloy HY 282 in the current study is consistent with result of other investigators $^{[2]}$ and thus appears to have played a sig- 
nificant role in the observed resistance of the alloy to post-weld heat treatment cracking.

\section{Conclusions}

(1) The precipitation rate of $\gamma^{\prime}$ phase in HY 282 alloy is rapid while the aging kinetics is comparatively slower than in IN $718+$ alloy.

(2) Apart from the $\mathrm{Al}+\mathrm{Ti}$ contents in $\gamma^{\prime}$ precipitation strengthening alloy, a major factor influencing PWHT cracking is the presence or absence of phases having strong or weak interface with the $\gamma$ matrix. Where the particle-matrix interface is strong, resistance to PWHT cracking may be enhanced.

(3) The commercially recommended PWHT procedure, developed for the new HY 282 alloy, appears to be adequate in mitigating PWHT cracking in laser welded specimen.

(4) Results of the cracking measurements obtained in the current study after the PWHT of the as-welded specimen are not in agreement with previous findings in some other precipitation strengthened alloys like IN $718+$ and IN 718 .

(5) The resistance of the new HY 282 alloy to PWHT cracking, despites the relatively rapid precipitation of the $\gamma^{\prime}$ strengthening phase, can be attributed to the absence of grain boundaries embrittling phases, such as: $\gamma-\gamma^{\prime}$ eutectic, laves and delta phases along interdendritic and grain boundaries regions during welding and PWHT.

\section{Acknowledgement}

The authors would like to thank Haynes International Kokomo USA, Standard Aero Ltd, Winnipeg for provision of study material and logistic support through Prof. O.A. Ojo of the University of Manitoba.

\section{REFERENCES}

[1] L.M. Pike, in: Proceeding to Superalloy 2008, De- velopment of Fabricable gamma-prime $\left(\gamma^{\prime}\right)$ Strengthened superalloy, R.C. Reed, K.A. Green, C. Pierre, T.P. Gabb, M.G. Fahrmann, E.S. Huron and S.A. Woodard, eds. The Minerals, Metals \& Materials Society, 2008.

[2] L.M. Pike, in: Proceeding to ASME Turbo Expo 2007, Montreal Canada. Paper No. GT2007-2826.

[3] K. Banergee, N.L. Richard and M.C. Chaturvedi, Metall. Mater. Trans. A 36 (2005) 1881.

[4] M. Prager and C.S. Shira, Welding Research Council Bulletin, Welding Research Council 128 (1962) 1.

[5] R.K. Shidu, N.L. Richards and M.C. Chaturvedi, Mater. Sci. Technol. 23 (2007) 202.

[6] L.O. Osoba and O.A. Ojo, Mater. Sci. Technol. 28 (2012) 431

[7] L.O. Osoba, R.G. Ding and O.A. Ojo, Mater. Charact. 65 (2012) 93.

[8] L.O. Osoba, R.G. Ding and O.A. Ojo, Metall. Mater. Trans. 43 (2012) 4281.

[9] D.S. Duval and W.A. Owezarski, Weld. Res. Suppl. 48 (1969) 10s.

[10] Y. Nakao, Trans. Jpn. Weld. Soc. 19 (1988) 1.

[11] O.I. Idowu, Ph.D. Dissertation, University of Manitoba, 2010.

[12] R. Thamburaj, W. Wallace and J.A. Goldack, Int. Met. Rev. 28 (1983) 1.

[13] L.C. Lim, J.Z. Yi, N. Liu and Q. Ma, Mater. Sci. Technol. 18 (2002) 407.

[14] J.B. Calton and M. Prager, Weld. Res. Council Bull. 150 (1970) 13.

[15] D. Krenz, A.T. Egbewande, H.R. Zang and O.A. Ojo, Mater. Sci. Technol. 27 (2011) 268.

[16] J.J. Schirra, R.H. Caless and R.W. Hatala, in: Proceedings on Superalloys 718, 625, 706 and Various Derivatives, E.A. Loria ed., The Minerals, Metals and Materials Society, 1991.

[17] R.L. Kennedy, in: Proceedings on Superalloy, 718, 625, 706 and Derivatives 2005, E.A. Loria ed., The Minerals, Metals and Materials Society, 2005, pp. 114.

[18] L.M. Zimina, Metalloveden. Term. Obrab. Met. 11 (1977) 2. 